Research Article

\title{
Innovation Path of Leasing Trade under Smart Logistics Technology by Big Data Analysis
}

\author{
Yanan Song $\mathbb{D I}^{1}$ and Xiaolong Hua $\mathbb{i D}^{2}$ \\ ${ }^{1}$ School of Business, Macau University of Science and Technology, Macao, China \\ ${ }^{2}$ School of Finance, Inner Mongolia University of Finance and Economics, Huhhot, China \\ Correspondence should be addressed to Xiaolong Hua; hxl@imufe.edu.cn
}

Received 14 August 2021; Revised 3 September 2021; Accepted 11 September 2021; Published 28 September 2021

Academic Editor: Sang-Bing Tsai

Copyright (c) 2021 Yanan Song and Xiaolong Hua. This is an open access article distributed under the Creative Commons Attribution License, which permits unrestricted use, distribution, and reproduction in any medium, provided the original work is properly cited.

\begin{abstract}
With the continuous development of big data and the increasing maturity of e-commerce, people's requirements for modern logistics are becoming increasingly diversified. Conventional modern logistics service level is insufficient to meet the needs of consumers. Therefore, research on the innovative path of big data analysis of leasing trade under smart logistics technology is increasingly important. Smart logistics pays much attention to the integration of the Internet of Things, sensor networks, and the existing internet and realizes the automation, visualization, controllability, intelligence, and networking of logistics through sophisticated, dynamic, and scientific management, thereby improving resource utilization rate and productivity level, creating a more comprehensive connotation of social value. This work aimed to study the use of smart logistics technology to make electric car leasing to a higher level and to innovate the promotion and use mode of leasing trade. A shared business model of electric vehicles was proposed based on the internet and smart logistics technology. The experimental results showed that smart logistics technology contributes to exploring and expanding the role of electric vehicles in solving group users' short-distance travel and improving an urban transportation system. It could offer a basis for nationwide promotion, thus promoting the development of the new energy vehicle industry and testing the practicability of the model. Regarding the improvement of the sample information system, the experimental results showed that the user's full satisfaction is approximately $50 \%$, while there remain the customers who would ask for further improvements. Besides, most customers believe that the accuracy and sensitivity of the existing invehicle information display need to be enhanced.
\end{abstract}

\section{Introduction}

1.1. Background. With the continuous development of computer technology, big data-related technologies are becoming more and more mature, which helps to promote the development of the logistics industry. Compared with western developed countries, the market development of China's leasing industry is still immature. It is found that the most prominent problem restricting the sustainable and healthy development of China's leasing trade companies at this stage is the blockage of leasing trade channels. The rise of smart logistics technology offers a good channel for the leasing industry to take advantage of smart logistics, expand lease transaction channels, and improve capital turnover efficiency. With the rapid popularization of various families on the Internet and the rapid development of e-commerce service platforms such as Taobao and Jingdong, it has brought not only huge development prospects to the logistics industry but also challenges to the development of more humanized services. Besides, conventional modern logistics itself has many issues, such as high operating costs and lagging services. With the proposal of smart earth and smart cities and the rapid development of Internet of Things technology, smart logistics has also begun to receive attention and research.

Modern logistics considers not only the delivery of goods from the producer to the consumer but also the procurement of raw materials from the supplier to the producer, as well as the producer's own transportation, storage, and information in the product manufacturing process. In addition, 
comprehensively improving economic benefits and efficiency are also the focus of consideration of modern logistics. Smart logistics can reduce operating costs, improve logistics profit and efficiency, and improve logistics service quality.

1.2. Significance. Currently, the demand for information technology applications is increasing. With the improvement of users' perceived demand, the service demand of the logistics industry is also increasing. Therefore, higher requirements were put forward for logistics and distribution services, and the corresponding index system also needed to be changed in time. More attention should be paid to the convenience of customer service and the improvement of service effect to make the evaluation method more accurate. The intelligent logistics system based on the Internet of Things can not only optimize the existing business of logistics enterprises, increase the profit point of the existing business, and create new profit sources but also reduce the operating cost of logistics enterprises. Automatic perception and control of the logistics process can save manpower and management cost in the logistics process and effectively control the cost of information collection, transmission, and processing. It can effectively solve the technical bottleneck, establish a perfect logistics service system, and meet the market demand.

1.3. Main Content. Through the collection of relevant information and data, the development status and business model of the leasing trade under smart logistics technology were analyzed. Combined with specific cases, the operating mode of leasing trade platform under smart logistics technology was compared and analyzed, and the enlightenment of leasing trade business mode novelty under smart logistics technology was obtained. The integration of Internet and leasing trade should focus on further expanding leasing trade channels, reducing leasing trade costs, and strengthening risk control, with equal emphasis on novelty and security. At the same time, the sustainable development of smart logistics leasing trade can be promoted by building an e-commerce trading platform for leasing goods and deepening the integration of smart logistics and leasing trade, and China's real economy can be better served. Based on smart logistics technology, this work proposed a shared business model of electric vehicles. The background information system and related products and equipment can be verified under actual working conditions. Also, it can contribute to exploring and expanding the role of electric vehicles in solving group users' short-distance travel and improving the urban transportation system. It offers a basis for nationwide promotion, thus promoting the development of the new energy vehicle industry and testing the practicability of the model.

\section{Related Work}

Smart logistics is an inevitable trend in the development of modern logistics. Firstly, the concepts of low-carbon, environmental protection, green, and resource recycling are becoming increasingly popular in society, and an increasing amount of time is used in various industries. In modern logistics, concepts such as green logistics and low-carbon logistics are also valued. Kirch et al. pointed out that the demand for automatic identification and positioning of logistics objects and status monitoring as a data source for secure supply chain documents and control is increasing. By using such technologies, smart logistics areas can be created for logistics and production processes. This work described a way to define such smart logistics area. As an example of smart logistics area application, two RFID basic use cases were described. Thus, it showed the potential of using smart logistics technology. However, the promotion of smart logistics still needs some time [1]. Lee indicated that products that require temperature control in distribution and logistics are commonly referred to as "fresh logistics," which is to maintain freshness in a systematic management process. The thermal management technology used in the logistics industry to cope with low temperature and freezing is called a cold chain. It is called a cold chain because the temperature control is continuously carried out on the entire chain from the producer to the consumer. Currently, the cold chain focuses on the spatial scale, such as warehouses and distribution vehicles. RFID based sensor tag and intelligent cold chain system were developed. These two used cases can be applied to each product, tracing pedigree and managing freshness units separately. The intelligent cold chain system is applied to eggs and cosmetics to evaluate the economic feasibility, but the system is not perfect enough and still needs to be controlled by people [2]. Agyabeng-Mensah et al. pointed out that this work mainly studied the relationship between information technology, supply chain quality integration, green logistics management, and organizational performance. The mediating effect of supply chain quality integration and green logistics management was further investigated. The unit of analysis is small and medium enterprises in Ghana. Smart PLS-3 was used to analyze survey data collected from 280 tactical and strategic managers through questionnaires. All assumptions were supported and accepted. The analysis results established a positive correlation between exogenous variables and endogenous variables. It is found that supply chain quality integration and green logistics management play an intermediary role between information technology and organizational performance. Besides, the results show that supply chain quality integration plays an intermediary role in the relationship between information technology and organizational performance, while supply chain quality cannot be guaranteed at all times [3].

\section{Smart Logistics Distribution Route Planning Method}

3.1. Overview of the Smart Logistics System. When talking about smart logistics, we have to mention smart logistics system and smart logistics $[4,5]$. Smart logistics system is the operation guarantee of smart logistics and the upgrading stage of understanding smart logistics. Smart logistics is another term for smart logistics in different times, and its essence is equivalent to smart logistics. "Smart logistics" pays 
more attention to the integration of the Internet of Things, sensor networks, and the existing Internet and realizes the automation, visualization, controllability, intelligence, and networking of logistics through fine, dynamic, and scientific management, thereby improving Resource utilization and productivity levels, creating a more comprehensive connotation of social value. Build a smart society by building complete smart logistics.

Smart logistics and smart logistics system have the same connotation and concept, while the background and usage scenarios are different. In the discussion of breaking the institutional constraints, Zhao Liquan believes that smart logistics refers to a process of intelligently moving goods from the seller to the buyer, as shown in Figure 1. Its purpose is to obtain the best logistics service for the seller, realize the reasonable allocation of natural and social freedom, reduce energy consumption, and protect the environment. Therefore, logistics can achieve a state of sustainable development, thus forming a relatively complete smart social logistics management system. At the same time, some scholars proposed that although the concept of "smart logistics" has been widely mentioned in the industry and the relevant explanations are diverse and different, they basically stay at the demand for smart logistics technology, as shown in Figure 2. Gong Fajin believes that smart logistics is based on modern logistics and integrates logistics information by using the Internet of Things, computer technology, and information processing technology. Through the information system and automation equipment, it can independently complete the basic logistics business, such as order processing and goods distribution, thus achieving the development goal of economy, reliability, efficiency, and environmental protection.

\subsection{Introduction to Ant Colony Film Calculation. Due to the} use of conventional heuristic algorithms, the quality of the solution obtained by solving VRPTW is not high $[6,7]$. According to the ant colony algorithm, it shows a positive feedback process in path optimization (i.e., when a better solution is searched, it can converge to the optimal solution at a faster speed) [8]. However, path optimization also has its shortcomings. When the target point is unreachable, it will cause a lot of performance consumption. Therefore, an ant colony algorithm membrane computing (ACAMC) algorithm was proposed combined with MC's strong parallel global search ability. The design took the "evolutionary communication" (ECMC) system in MC as the framework structure, embedded the ant colony system in the basic membrane as the subalgorithm in the membrane, and improved the algorithm performance through communication rules between membranes [9]. Finally, the algorithm was analyzed and tested with test data.

3.2.1. Ant Colony Algorithm. Ant colony algorithm (ACA) was observed by Baek et al. [10]. In the process of foraging, ant colonies can always find the shortest walking path between their nest and food. Therefore, a new simulated evolutionary algorithm was proposed.
Basic description of ACA: at the beginning of the iteration, $m$ ants are randomly placed in the distribution center, the pheromone on each distribution path is specified to be the same, $\tau_{i j}(0)=c$, and then according to the amount of pheromone remaining on the path by each ant, the heuristic information (the length of the path between two customers) selects the next destination and defines the probability of the ant transferring from point $i$ to point $j$ at time $t$ as follows.

Basic description of ACA: $m$ ants are randomly placed in the distribution center at the initial stage of iteration, the pheromones on each distribution path are the same, and $\tau_{i j}(0)=c$. Then, the next destination is selected according to the amount of pheromone left by each ant on the path and heuristic information (path length between two customers). At time $t$, the probability of ants moving from point $i$ to point $j$ is defined as follows:

$$
p_{i j}^{k}(t)= \begin{cases}\frac{\left[\tau_{i j}(t)\right]^{\alpha}\left[\gamma_{i j}(t)\right]^{\beta}}{\sum_{s \in J_{k}(i)}\left\{\left[\tau_{i s}(t)\right]^{\alpha}\left[\gamma_{i s}(t)^{\beta}\right]\right\}}, & j \in J_{k}(i), \\ 0, & \text { others. }\end{cases}
$$

Among them, $J_{k}(i)=\{1,2, \ldots, n\}-\operatorname{tabu}_{k}$ is the point set that the $k$ th ant can reach [11]. At this time, list tabu ${ }_{k}$ saves the points that have been visited. When all target points are saved in tabu $k$, ant $k$ is recorded to complete a one-week trip. After all ants complete a cycle, the pheromone update equation on the corresponding path is as follows:

$$
\begin{aligned}
\tau_{i j}(t+n) & =(1-p) \tau_{i j}(t)+\Delta \tau_{i j}, \\
\Delta \tau_{i j} & =\sum_{k=1}^{m} \Delta \tau_{i j}^{k} .
\end{aligned}
$$

If the path $i j$ is not passed, ant $k$ is recorded to complete a one-week trip; then, the value of formula $\Delta \tau_{i j}^{k}$ is zero, which is expressed as

$$
\Delta \tau_{i j}^{k} \begin{cases}\frac{Q}{L_{k}}, & \text { Ant } K \text { experienced } i j \text { in this tour, } \\ 0, & \text { otherwise. }\end{cases}
$$

In the equation, $Q$ is a normal number. $L_{k}$ is the $k$ th ant to walk the length of the trail on this tour. Equation (3) is called the ant cycle model [12]. It uses the overall information (i.e., it updates the pheromones on all paths after completing a cycle). The other two models that use local information are as follows:

$$
\Delta \tau_{i j}^{k} \begin{cases}\frac{Q}{d_{i j}}, & \text { Ant } K \text { experienced } i j \text { in this tour, } \\ 0, & \text { otherwise. }\end{cases}
$$




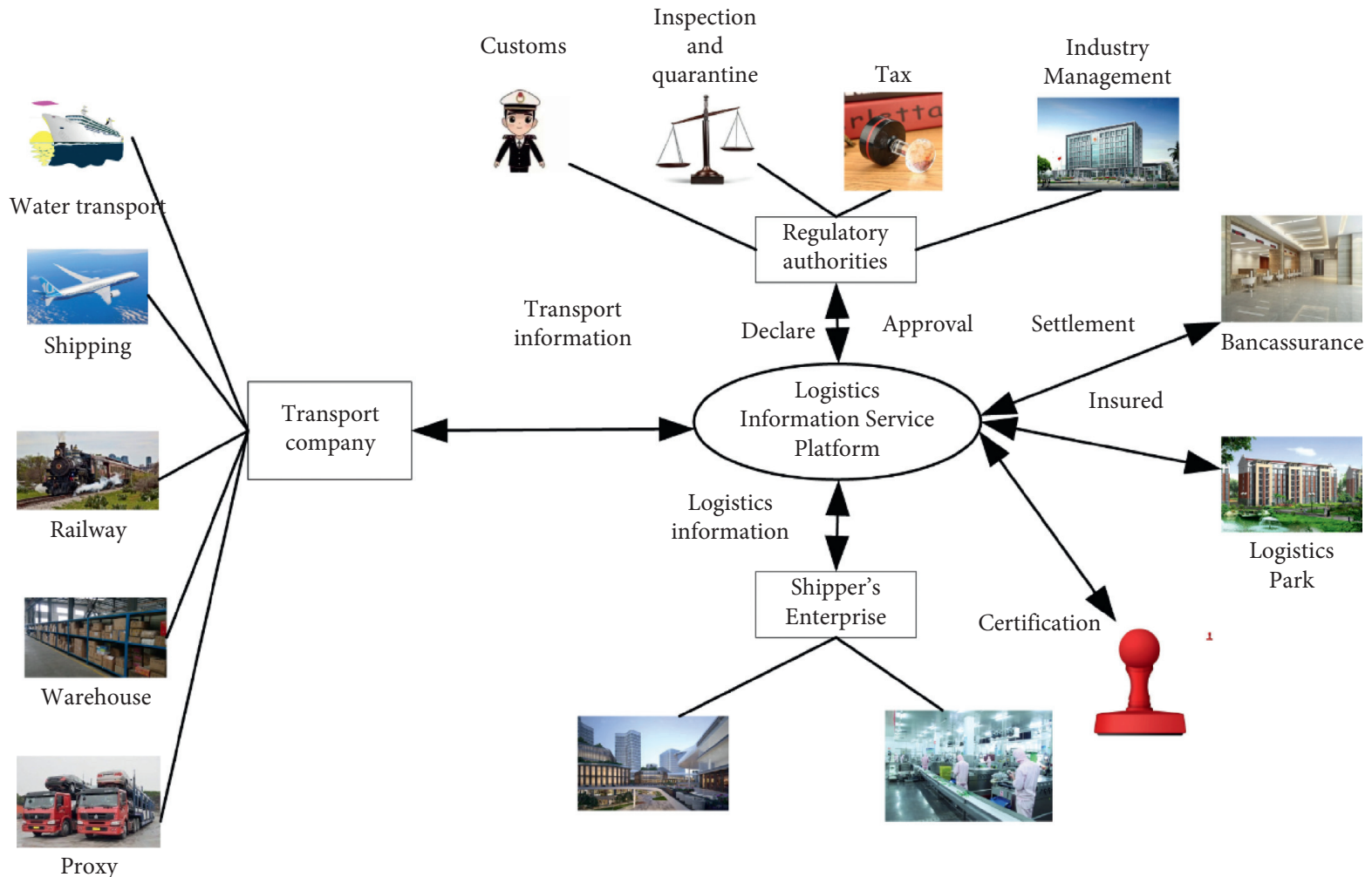

Figure 1: Traditional logistics information platform.

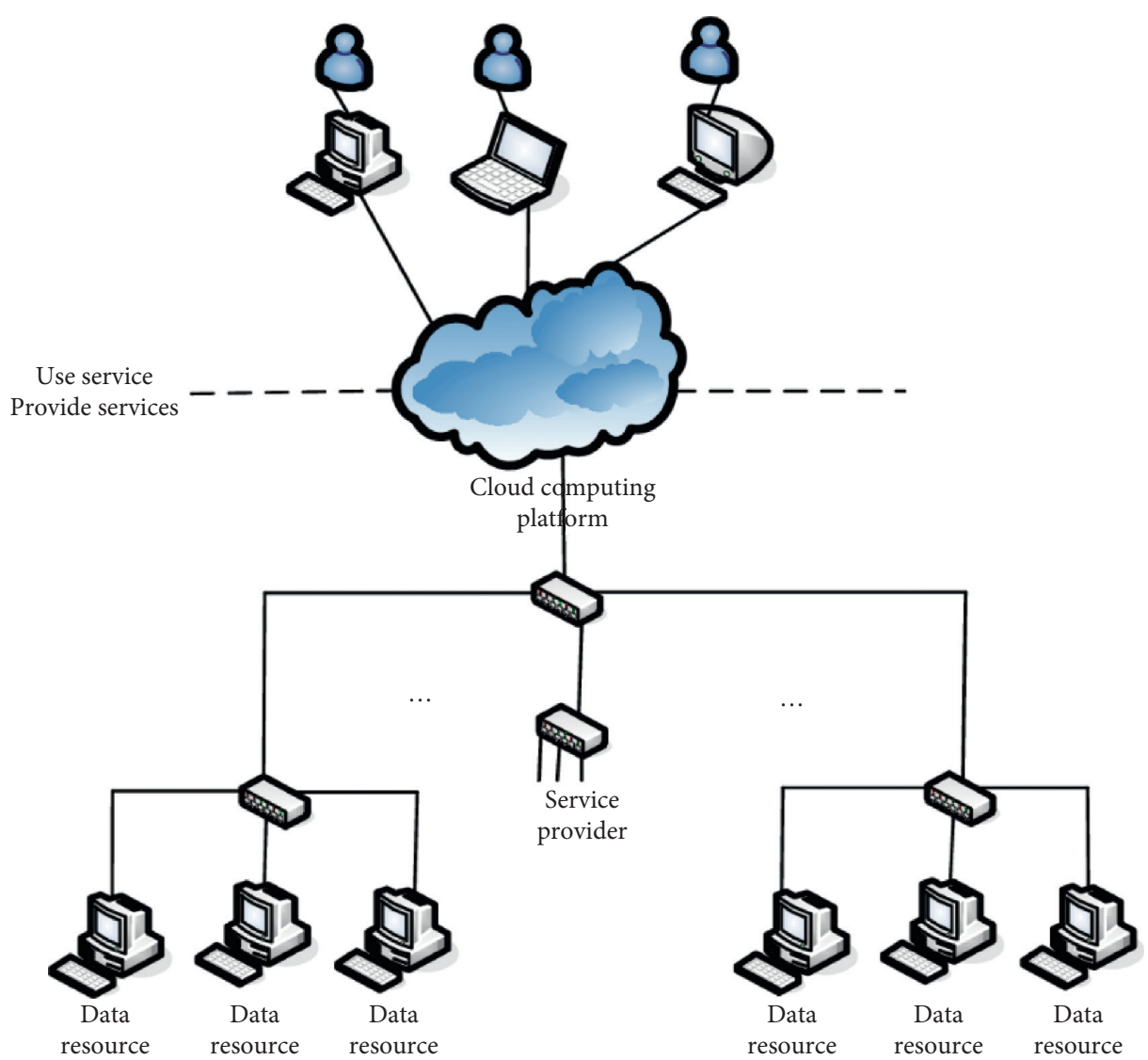

FIGURE 2: Smart logistics information platform. 
Ant-density model:

$$
\Delta \tau_{i j}^{k} \begin{cases}Q, & \text { Ant } K \text { experienced } i j \text { in this tour, } \\ 0, & \text { otherwise. }\end{cases}
$$

3.2.2. Description of Ant Colony Optimization Membrane Calculation. The membrane structure of the ECMC framework adopted by ACAMC is shown in Figure 3.

The interior of each basic membrane undergoes evolution processing at the same time. According to the actual chemical reaction of substances, it is abstracted into the rewriting rules in MC. The exchange rules between membranes and substances in membranes are called communication rules [13]. Dorigol and other researchers observed that the ant colony algorithm (ACA) can always find the shortest walking path between nest and food during foraging. Therefore, inspired by this, a new simulated evolutionary algorithm is proposed.

The system consists of an outer membrane and a base membrane. The base membrane has no membrane structure. At the initial point, there are initial individuals and rewriting rules on each matrix. The membrane subalgorithm can be calculated independently and in parallel. At the end of the iteration, the global optimal solution represented by the outer membrane becomes the final calculation result of the system.

\subsection{Path Planning Problem with Time Window Based on Ant Colony Optimization Film Calculation}

3.3.1. Path Planning Mathematical Model with Time Window. VRPTW is described by graph theory as follows: graph $G=(V, 4)$ is an omnidirectional graph. $v=(1,2, \ldots, N)$ is the node set. $A=\{(i, j) \mid i, j \in v\}$ is the path between customers, and 0 is the distribution center. Other node numbers represent the customer label to be served. The goal of the problem is to plan an optimal path set and meet the following constraints. Each route starts and ends at the distribution center. The loading of each vehicle shall not exceed the capacity limit $Q$ and reach the customer's location within the customer's time window.

Mathematical model:

$$
\begin{aligned}
& \min \sum_{k=1}^{k} \sum_{j=1}^{N} x_{i j}^{k}, \quad i=0, \\
& \min \sum_{i=1}^{N} \sum_{j=1}^{N} \sum_{k=1}^{k} c_{i j} x_{i j}^{k} .
\end{aligned}
$$

Restrictions:

$$
\begin{aligned}
& \sum_{j=1}^{N} x_{i j}^{k}=\sum_{j=1}^{N} x_{i j}^{k} \leq 1, \quad i=0, k \in\{1, \ldots, k\}, \\
& \sum_{k=1}^{k} \sum_{j=0}^{N} x_{i j}^{k}=1, \quad i \in\{1, \ldots, N\}, \\
& \sum_{k=1}^{k} \sum_{j=1}^{N} x_{i j}^{k}=1, \quad i \in\{1, \ldots, N\}, \\
& \sum_{j=1}^{k} d_{i} \sum_{j=0}^{N} x_{i j}^{k} \leq Q, \quad k \in\{1, \ldots, k\}, \\
& \sum_{i=1}^{N} \sum_{j=0}^{N} x_{i j}^{k}\left(t_{i j}+s_{i}+w_{i}\right) \leq l_{0}, \\
& \sum_{k=1}^{k} \sum_{j=0}^{N} x_{i j}^{k}\left(t_{i}+t_{i j}+s_{i}+w_{i}\right) \leq t_{j}, \quad j \in\{1, \ldots, N\}, \\
& e_{i} \leq t_{i}+w_{i} \leq l_{i}, \quad i \in\{1, \ldots, N\}, \\
& x=\left\{\begin{array}{l}
1, \quad \text { vehicle } k \text { from customer } i \text { to customer } j, \\
0, \quad \text { otherwise },
\end{array}\right.
\end{aligned}
$$


0

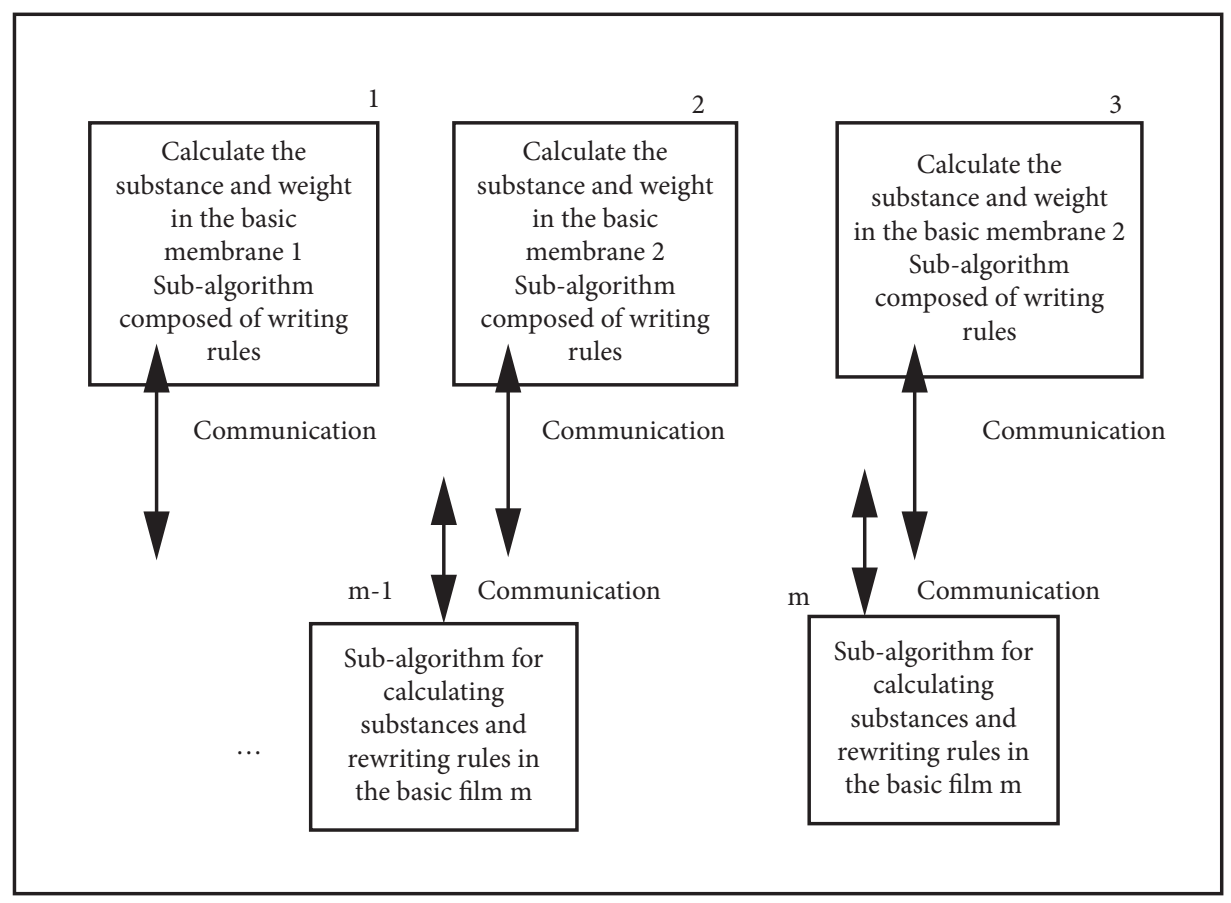

Figure 3: ECMC framework adopted by ACAMC.

Among them, $t_{i}$ represents the time when the vehicle arrives at customer $i . c_{i}$ is the customer. $s_{i}$ represents the delivery service time $s_{0}=0$ of customer $i$. Equations (6) and (7) are the objective functions of VRPTW, which are the minimum number of vehicles and transportation cost, respectively [14]. Equation (9) represents the maximum load limit, and equation (10) represents the maximum transportation time limit. Equations (11) and (12) are time window constraints.

\section{Rental Car Marketing Experiment}

4.1. Related Methods and Tools for Marketing Analysis. Many research methods and tools are needed to analyze corporate marketing models and strategies. The main research methods and tools used in this research are as follows.

4.1.1. PEST Analysis. In this context, the PEST analysis method was introduced, and it is usually used to analyze the external environment of an enterprise [15]. Among them, P refers to the analysis of the political environment faced by an enterprise in its operation and development, such as policies and regulations, relevant policy guidance, regime stability, and political atmosphere. These factors have a great impact on the development of enterprises, and thus this factor must be analyzed. $S$ is to analyze the social environment where the company is located. There are many social environments, mainly analyzing the social factors and group characteristics related to the company. $E$ represents the economy. The marketing environment is the various factors and trends that affect the marketing management capabilities of the company and target customers to establish and maintain a mutually beneficial relationship. It can be divided into a macro-marketing environment and a micro-marketing environment. $T$ is an analysis of the technical environment. If an enterprise wants to change its development strategy, produce new products, and change its marketing strategy, it must have certain technical conditions to support its change [16]. It would be better if there is no technical support. Therefore, technology is also a factor that an enterprise must consider in its background analysis. Figure 4 is a schematic diagram of the PEST analysis method. When analyzing the industry environment of a car rental company, this method was used to analyze its political, economic, social, and technical environment, thus grasping the current situation of a car rental company more clearly.

4.1.2. SWOT Analysis. Combined with the development of China's automobile industry and its advantages and disadvantages, the SWOT analysis method was introduced to demonstrate the development of China's automobile leasing industry, as shown in Figure 5 [17].

Four strategies can be derived through SWOT. SO strategy means that enterprises can give full play to their own advantages and have good market opportunities. This is the strategy that enterprises most want to adopt, and enterprises can make full use of their advantages. WO strategy refers to that enterprises cannot make full use of the appropriate opportunities for external development due to their own shortcomings. In this case, the enterprises should improve their own issues. WT strategy means that enterprises have their own weaknesses and the external environment is unfavorable [18]. ST strategy is a superior threat. It refers to a strategy made when one's own internal conditions are 


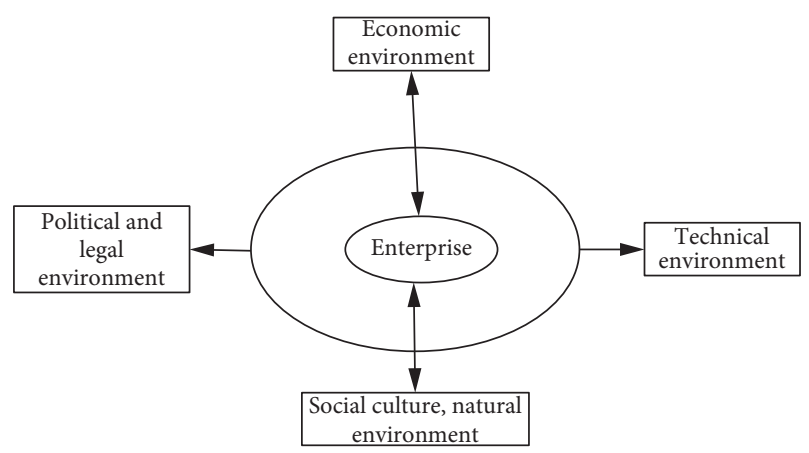

FIgURE 4: Schematic diagram of the PEST analysis.

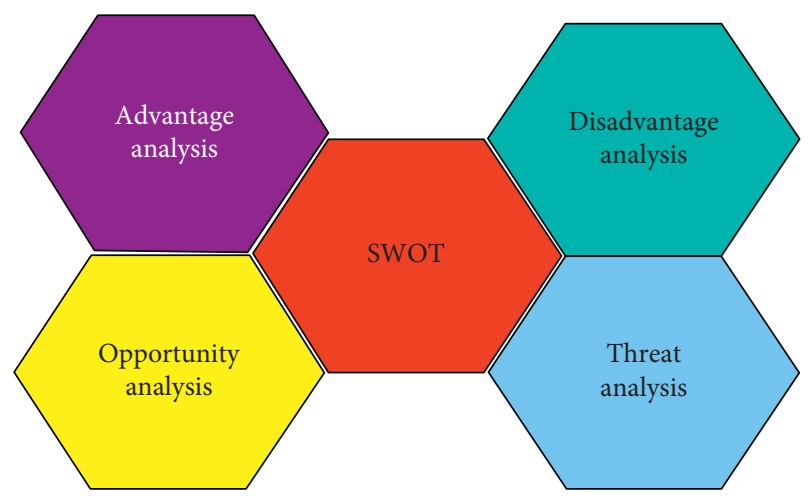

FIgURE 5: Schematic diagram of SWOT analysis.

superior and the external environment is threatened and uses one's own superiority to make up for external threats. In this case, enterprises should improve themselves while avoiding external environmental risks. In this context, the SWOT method was used to gradually analyze its strengths, weaknesses, opportunities, and threats when analyzing a car rental company's implementation of Internet marketing strategy, thus better helping a car rental company make specific decisions.

4.1.3. STP Analysis. STP analysis is the basis for the construction of the entire marketing strategy [19]. It must be based on detailed analysis to find the market positioning of their services and directly enter the target market, reducing entry assistance and entry costs. Regardless of its development status, any company must analyze the needs of customers in the market in detail and choose a suitable marketing strategy, as shown in Figure 6.

\subsection{Implementation of the Electric Car Rental Program.} By the end of October 2020, the company had 136 outlets in normal operation. The number of members is also gradually increasing. By the end of October, the total number of customers was 18,302, all of which were registered in real names. Moreover, the monthly order number of the company is also showing a good momentum of gradual growth [20]. The recent monthly membership growth and orders are as follows.
It can be seen from Figure 7 that the number of monthly registered members maintained a trend of slow fluctuations from January to July. The monthly order volume maintained linear growth. With the increase of monthly registered members, the order volume increased naturally.

Since August, the new member index has ended its steady fluctuations, and the growth rate has accelerated significantly. The growth rate $k$ of monthly orders is also significantly higher than before. The reasons for this are listed below.

The function of the product is improved and the operation mode tends to be stable. When the number of outlets and vehicles reaches a certain amount, the scale effect is generated. Media publicity channels have increased, and mainstream media attention has increased [21]. The secondary publicity effect after the number of users has accumulated to a certain level.

Accordingly, it can be concluded that January to March is the initial stage, April to July is the exploration stage, and August to October is the stable development stage. The growth period is expected to continue until the number of members reaches the estimated threshold. However, even if the number of members reaches the threshold, the monthly order volume is likely to continue to grow. After the growth period ends, there will be a transition to a stable period. As a result, the total number of users and orders will maintain a dynamic balance, and the accuracy of big data in measuring users' car use law will be improved.

\section{Research and Analysis of User Experience Effect}

5.1. Sources of Customer Data. First, the sample quantity information data will be collected until early October 2020, and the sampled users will be surveyed by telephone interview. There are 21 questions in this questionnaire survey. The main purpose is to understand users' experience of using vehicular information terminals, charging pile remote information monitoring module, and sharing application software and investigate the basic situation and use intention of some users [22]. The basic situation is summarized as follows.

Figure 8 describes the basic information preliminary summary of all the quantitative survey sample subjects in this study. The respondents are preliminarily divided by gender, including 10 women, accounting for $13.3 \%$ of the total sample. With regard to age, there are 30 respondents aged $18-25$, accounting for $40 \%$ of the total sample. There are 24 respondents aged $26-30$, accounting for $32 \%$ of the total sample. There are 21 respondents over the age of 30 , accounting for $28 \%$ of the total sample. In addition, the order information, education, occupation, income status, and vehicle ownership status of these samples were also investigated. Table 1 shows examples of user usage times and user groups.

Second, the call center's opinions were collected and summarized. At the same time, 100 complaint records of complaint centers were randomly retrieved, and then the relevant deficiencies and aspects to be developed in the 


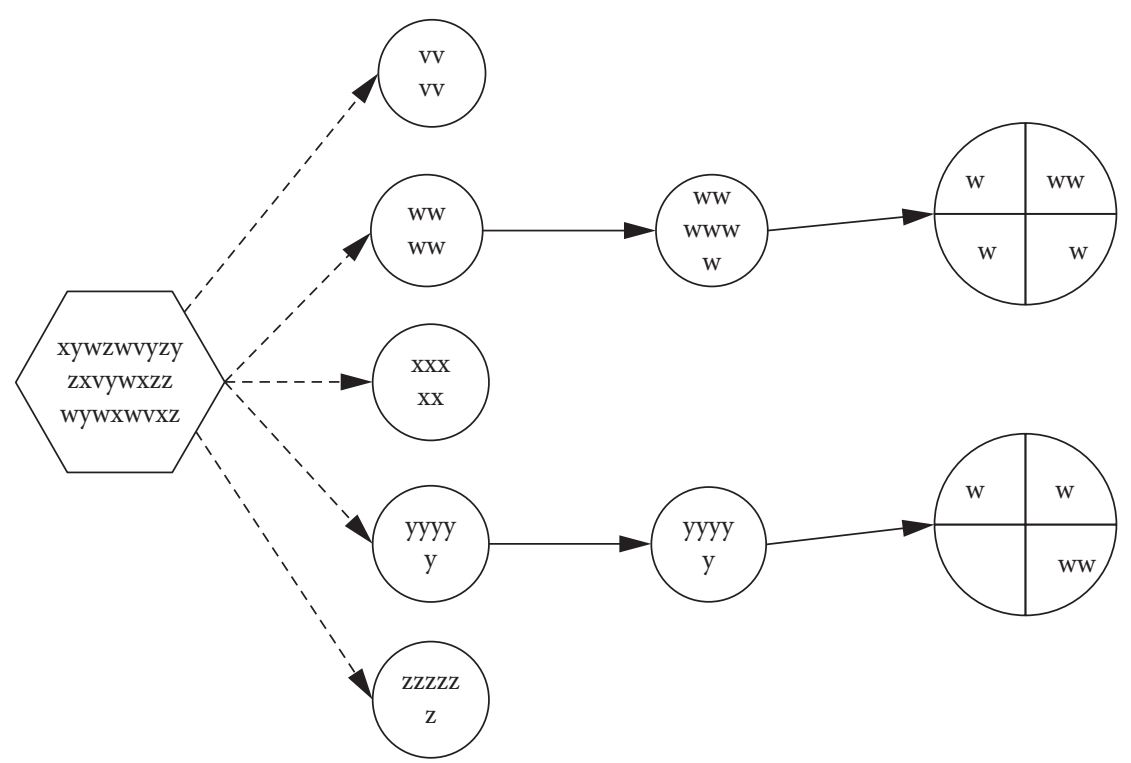

FIGURE 6: Schematic diagram of STP analysis.

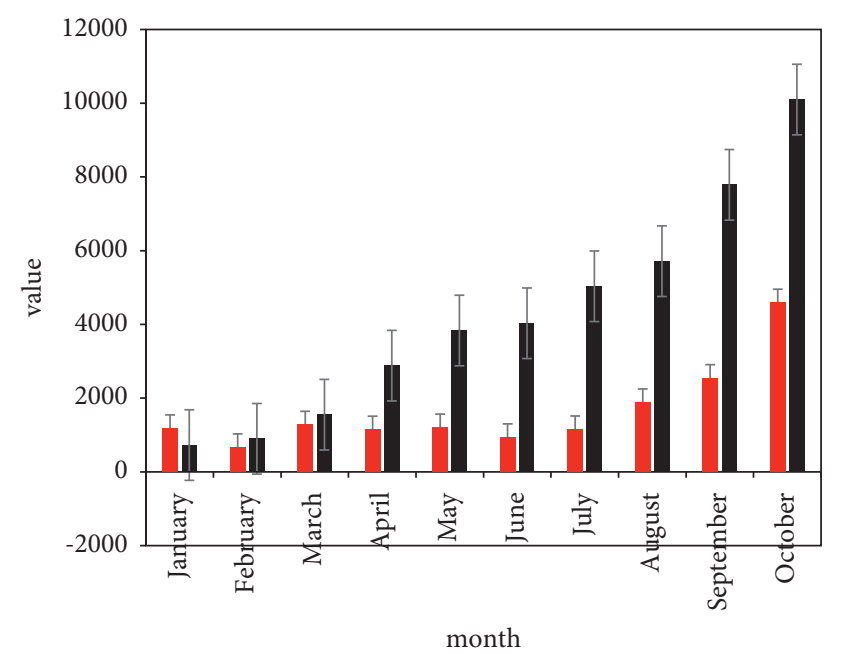

- Number of registered members

- Number of order

Figure 7: The number of monthly registered members and monthly orders in 2020 .

operation process were obtained through the statistics and analysis of these complaints and suggestions. Through comparative analysis, it is mutually confirmed with the results of our quantitative investigation, thus making the conclusion more reasonable and objective.

Third, data on sample qualitative information were collected. In order to have a deeper understanding of user's experience in the use of on-board information terminal, charging pile remote monitoring module, rental and sharing app software, and so forth, two users who have used the project products many times were found and interviewed for in-depth follow-up investigation [23]. In the process of research, users' personal experience of leasing and sharing products was further understood through sorting and analyzing the interview content, and the aspects that need to be updated and improved in the products were obtained.

Table 2 describes the basic information of the interviewees in this qualitative survey. The interviewees are arranged according to the actual interview order. There are two interviewees. One interviewee $A$ is a master in Tongji University (Tongji University is a major source of customers, with typical significance), and the other interviewee $B$ is a white-collar employee of a company, who is a common typical target user group.

\subsection{Data Processing and Preliminary Analysis}

5.2.1. Basic Information Processing and Preliminary Analysis of the Sample. It can be seen from Figure 9 that the customer's order efficiency is relatively high in the process of using products, while there are still unsuccessful orders. This may be due to the influence of bad network signal transmission at that time, the operation error of the user when placing an order, the error of background data processing, and so forth. [24]. However, it also shows that there is still room for improvement in the affinity of related products and the integrity of services. Customers are mainly distributed among highly educated people. Due to their relatively high education level, it is relatively simple to adapt and accept the new model. On the other hand, there will be corresponding awareness in product maintenance, which can well maintain the sustainability of rental sharing projects.

5.2.2. Customer Experience Data Processing of In-Vehicle Information Terminals. It can be seen from Figure 10 that most customers are satisfied with the existing vehicle information display, while some customers think it needs to be improved. It can be seen that users have higher requirements for the quality of vehicle information terminal information. 


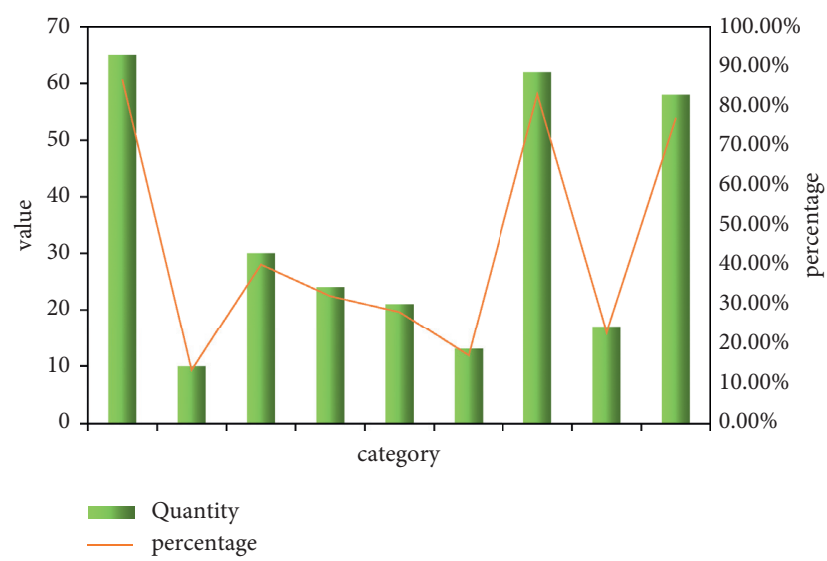

FIGURE 8: Summary table of basic customer information for quantitative research.

TABLE 1: Summary of users of different times and summary of user groups.

\begin{tabular}{|c|c|c|c|c|c|c|}
\hline \multirow{2}{*}{ Item category } & \multicolumn{2}{|c|}{ Gender } & \multicolumn{2}{|c|}{ Usage count } & \multicolumn{2}{|c|}{ User group } \\
\hline & Male & Female & Only once & Repeatedly & Student & Worked \\
\hline Quantity (person) & 65 & 10 & 13 & 62 & 17 & 58 \\
\hline Percentage & $86.7 \%$ & $13.3 \%$ & $17 \%$ & $83 \%$ & $23 \%$ & $77 \%$ \\
\hline
\end{tabular}

TABLE 2: The relevant basic information of the interviewees.

\begin{tabular}{lccccccc}
\hline Respondents & Gender & Age & Profession & $\begin{array}{c}\text { Annual } \\
\text { income }\end{array}$ & $\begin{array}{c}\text { Vehicle } \\
\text { ownership }\end{array}$ & Purpose of car & Times of car \\
\hline Male & 22 & $\begin{array}{c}\text { Pursuing } \\
\text { master }\end{array}$ & No & No car & $\begin{array}{c}\text { To the business district near the } \\
\text { campus }\end{array}$ & $\begin{array}{c}\text { See friends from a distance across } \\
\text { the district }\end{array}$ & $\begin{array}{c}\text { 5+ (including illegal } \\
\text { vehicles) }\end{array}$ \\
\hline$B$ & Male & 26 & Staff & 70 thousand & No car & Commute & $20+$ \\
\hline
\end{tabular}

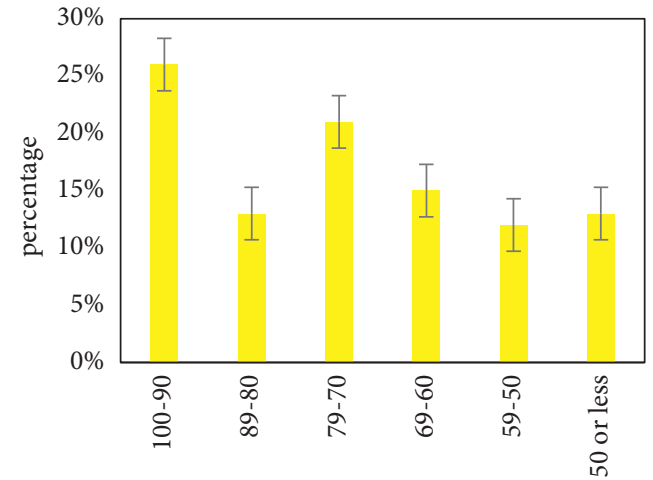

interval (\%)

Order success rate

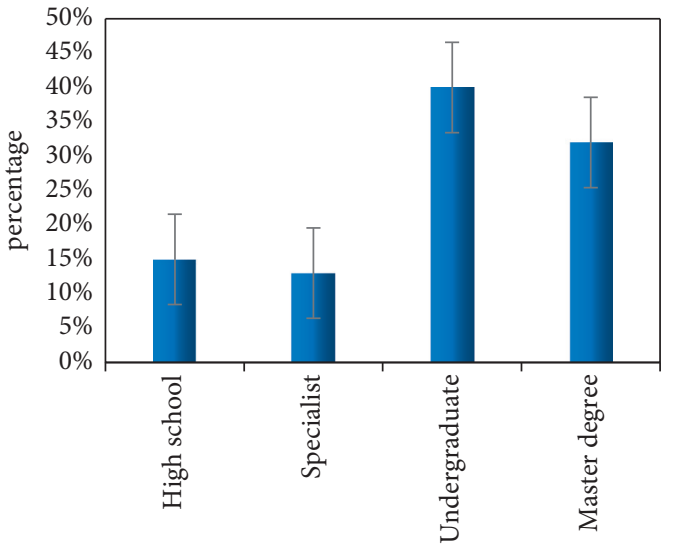

Highest education

FIGURE 9: Sample order success rate and sample education distribution.

Figure 10 in question 1 shows that the user's full satisfaction is approximately 50\%, while there remain customers who would ask for further improvements. It can be seen from
Figure 10 that most customers believe that the accuracy and agility of the existing in-vehicle information display need to be strengthened. On the other hand, the ability to remind the 


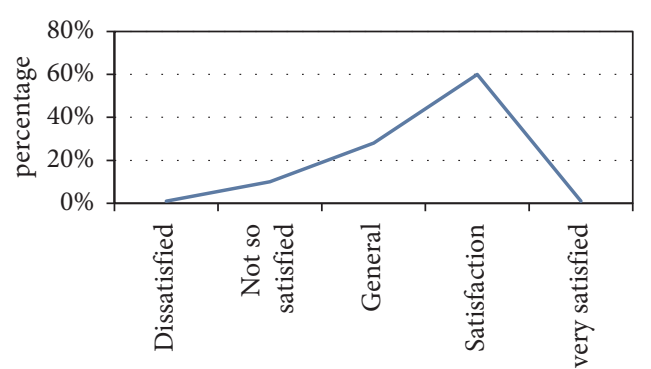

In-vehicle information display satisfaction

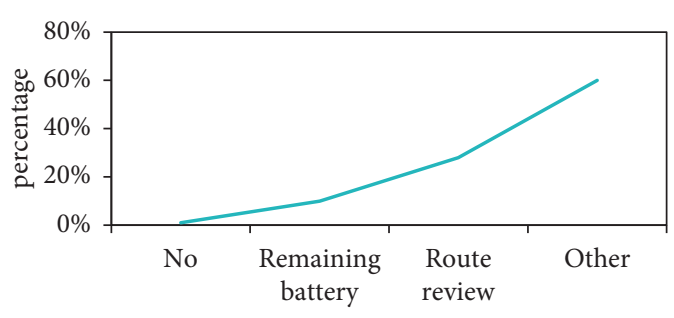

Areas that need to be improved in-vehicle information systems

FIgURE 10: Vehicle information display satisfaction and a summary of suggestions for improving the system.
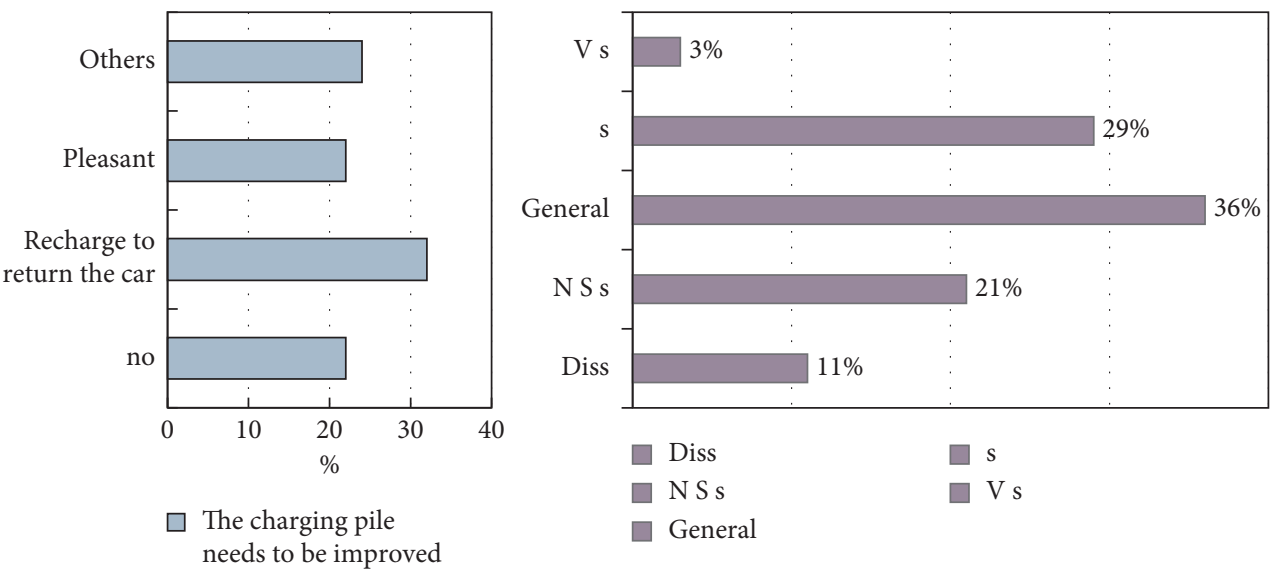

FIGURE 11: Suggestions for the improvement of charging facilities and satisfaction with the popularity of charging facilities.

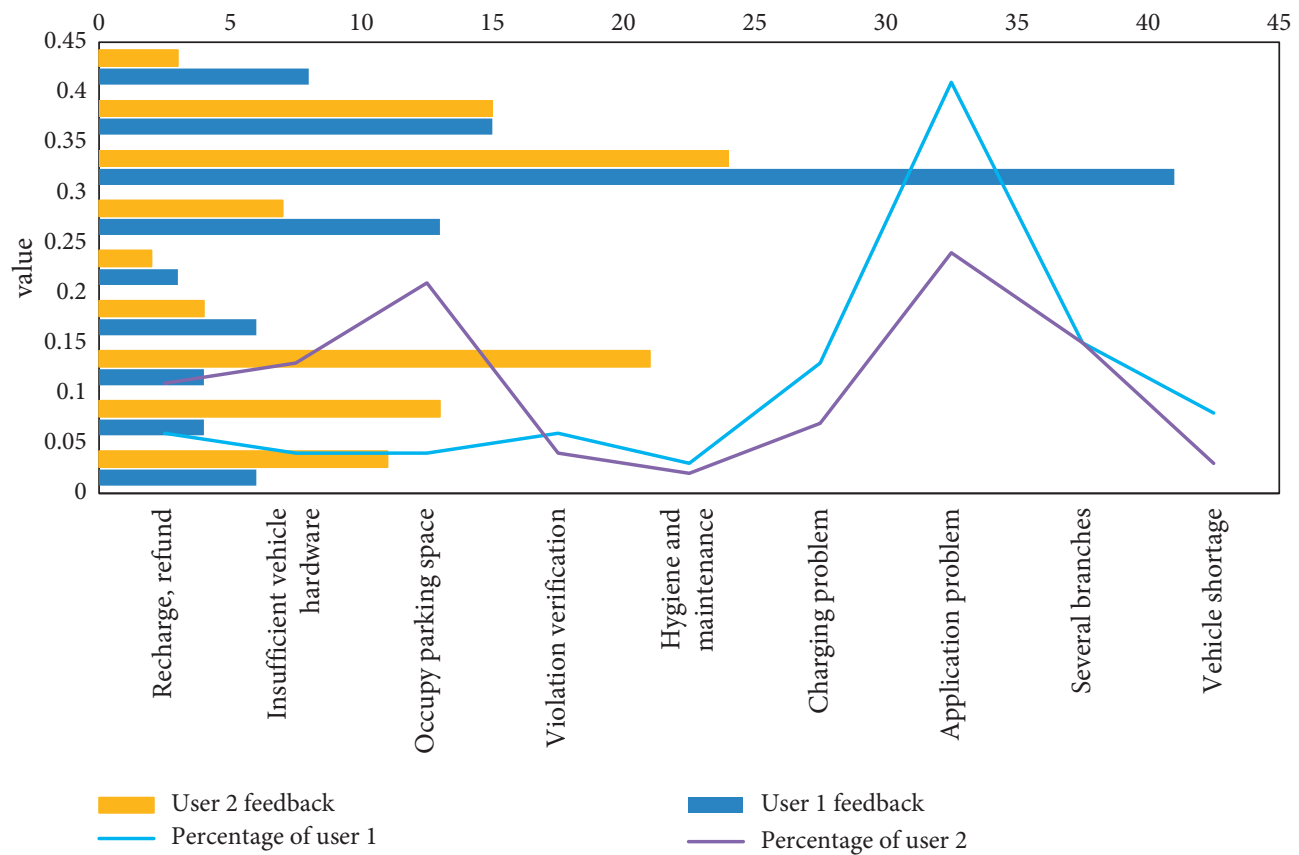

FIGURE 12: Summary of feedback questions from the call center sample. 
remaining power of electric vehicles and the ability of the vehicle to travel routes is also particularly concerned.

\subsubsection{Customer Data Processing for the Charging Pile Remote} Information Monitoring Module. The areas where the charging pile needs to be improved are shown in Figure 11. Although the excellent friendliness and convenience of the charging pile are reflected in question 1 , users still encounter some inconveniences in the use process; for example, the vehicle is often in an uncharged state. Therefore, users put forward valuable suggestions such as charging before returning the car and eye-catching tips in the survey. Among them, nearly one-third of the respondents believe that the vehicle can only be returned after charging, which has strengthened the user's consciousness and ensured the sustainable use of the vehicle. Users are not very satisfied with the penetration rate of charging piles. However, with the company's continuous development, the continuous increase of customers, and the continuous improvement of customer demand, the company is stepping up the spread of outlets throughout Shanghai to facilitate users' travel.

5.3. Handling and Analysis of Complaint and Suggestion Records. In the background random user complaint and suggestion records, APP software problems still account for a large proportion, and most of the opinions are about signal transmission. It can be seen from Figure 12 that there are still great developments in the performance improvement of APP software.

\section{Conclusion}

With the continuous development of China, many cities are pioneering and enterprising. However, many issues such as traffic congestion, environmental pollution caused by automobile exhaust, and tight use of vehicle parking spaces slow down the pace of development and always affect the lives of ordinary people. The leasing of electric vehicles, a vehicle traffic operation mode rising in China recently, has the potential to solve problems such as congestion, pollution, and difficult parking. Of course, the time-sharing rental model of electric vehicles is exactly in line with the current development needs and people's needs in many rapidly developing cities in China. Based on smart logistics technology, a shared business model of electric vehicles was proposed. Accordingly, the project has developed a new energy vehicle rental sharing information system, special vehicle, charging pile information terminal equipment, user app application software, and so on. Finally, the timesharing leasing scheme under the shared business model was studied. The background information system and related products and equipment can be verified under actual working conditions. Also, it can contribute to exploring and expanding the role of electric vehicles in solving group users' short-distance travel and improving the urban transportation system. It offers a basis for nationwide promotion, thus promoting the development of the new energy vehicle industry and testing the practicability of the model. In this context, the future business model of the car rental sharing information system was studied. The application experience obtained from the promotion of this model in major domestic cities will strongly promote a city to become a leading new energy vehicle friendly city in China. At the same time, the collaborative development law and model framework among key elements, such as new energy vehicles, charging facilities, operation platform, and users, will also obtain a complete and practical method. In the logistics distribution system, the vehicle routing problem is an extremely complex optimization problem. This work only makes a preliminary study on the vehicle routing problem, and the results obtained are still imperfect. Therefore, there is still a lot of work to be done. Vehicle routing problems have been widely applied, and the future research direction is to explore the solution methods of different vehicle routing problems, such as low-carbon path planning and vehicle routing problems with delivery requirements. Under the background of the era of big data, the development of commerce and logistics is facing new opportunities. Therefore, we must fully seize this opportunity to use the advantages of big data and integrate it with smart logistics technology to promote the efficient development of logistics enterprises.

\section{Data Availability}

The data used to support the findings of this study are included within the article.

\section{Conflicts of Interest}

The authors declare no conflicts of interest.

\section{References}

[1] M. Kirch, O. Poenicke, and K. Richter, "RFID in logistics and production-applications, research and visions for smart logistics zones," Procedia Engineering, vol. 178, pp. 526-533, 2017.

[2] S. H. Lee, "Study on RFID based smart cold chain system," Journal of Platform Technology, vol. 5, no. 1, pp. 23-32, 2017.

[3] Y. Agyabeng-Mensah, E. Ahenkorah, and G. Korsah, "The mediating roles of supply chain quality integration and green logistics management between information technology and organisational performance," Journal of Supply Chain Management Systems, vol. 8, no. 4, pp. 1-17, 2019.

[4] G. Webber, "Tough" 2017 for charter market due to new alliances," Container Shipping \& Trade, vol. 6, no. 2, pp. 10-11, 2017.

[5] P. Lacourbe, "Durable goods leasing in the presence of exporting used products to an international secondary market," European Journal of Operational Research, vol. 250, no. 2, pp. 448-456, 2016.

[6] M. Kutlu, T. Elsayed, and M. Lease, "Intelligent topic selection for low-cost information retrieval evaluation: a new perspective on deep vs. shallow judging," Information Processing \& Management, vol. 54, no. 1, pp. 37-59, 2018.

[7] G. Knowler, "Port of melbourne lease fetches USD 9.7 billion," Fairplay, vol. 387, no. 6888, pp. 26-27, 2016.

[8] A. C. W. Baldwin, H. R. Mallidi, J. C. Baldwin et al., "Through the looking glass: real-time video using "smart" technology 
provides enhanced intraoperative logistics," World Journal of Surgery, vol. 40, no. 1, pp. 242-244, 2016.

[9] R. Michel, "Wearables come in for a refit: technologies including smart glasses and real-time locating are shaking up industrial wearable computers, while more traditional wearables like forearm-mounted terminals evolve to take advantage of android, touchscreens and other technology," Logistics Management, vol. 56, no. 4, pp. 44-48, 2017.

[10] S. I. Baek, H. R. Shin, M. H. Park, and I. C. Doo, "A study on the management of drug logistics using beacon technology," Advanced Science Letters, vol. 24, no. 3, pp. 1979-1985, 2018.

[11] K.-D. Thoben, S. Wiesner, S. Wiesner, and T. Wuest, "Industrie 4.0" and smart manufacturing-a review of research issues and application examples," International Journal of Automation Technology, vol. 11, no. 1, pp. 4-16, 2017.

[12] Y. Y. Li and Y. S. Huang, "Research and application of cold chain logistics technology of medical supplies based on IOT," Basic and Clinical Pharmacology and Toxicology, vol. 119, no. S4, p. 47, 2016

[13] N. Schmidtke, E. Glistau, and F. Behrendt, "Magdeburg logistics model-the smart logistics zone as a concept for enabling logistics 4.0 technologies," Advanced Logistic Systems-Theory and Practice, vol. 13, no. 1, pp. 7-16, 2019.

[14] M. Humayun, N. Jhanjhi, B. Hamid, and G. Ahmed, "Emerging smart logistics and transportation using IoT and blockchain," IEEE Internet of Things Magazine, vol. 3, no. 2, pp. 58-62, 2020.

[15] L. King, "Teknowlogi launches A.I. platform for smart logistics decisions," Air Cargo World, vol. 107, no. 7, p. 10, 2017.

[16] I. Roll and R. Wylie, "Evolution and revolution in artificial intelligence in education," International Journal of Artificial Intelligence in Education, vol. 26, no. 2, pp. 582-599, 2016.

[17] A. Jeavons, "What is artificial intelligence?" Research World, vol. 2017, no. 65, p. 75, 2017.

[18] H. Lu, Y. Li, C. Min, H. Kim, and S. Serikawa, "Brain intelligence: go beyond artificial intelligence," Mobile Networks and Applications, vol. 23, no. 7553, pp. 368-375, 2017.

[19] D. Hassabis, D. Kumaran, C. Summerfield, and M. Botvinick, "Neuroscience-inspired artificial intelligence," Neuron, vol. 95, no. 2, pp. 245-258, 2017.

[20] L. D. Raedt, K. Kersting, S. Natarajan, and D. Poole, "Statistical relational artificial intelligence: logic, probability, and computation," Synthesis Lectures on Artificial Intelligence and Machine Learning, vol. 10, no. 2, pp. 1-189, 2016.

[21] Y. Ma, E. Lee, and R. Yuen, "An artificial intelligence-based approach for simulating pedestrian movement," IEEE Transactions on Intelligent Transportation Systems, vol. 17, no. 11, pp. 1-12, 2016.

[22] F. Lubonja, B. Gjylameti, and S. Kurti, "Financial leasing in albania and the impact that internal factors of a SME would have on the probability to be financed by lease," Central European Economic Journal, vol. 6, no. 53, pp. 189-198, 2020.

[23] R. Liu, B. Yang, E. Zio, and X. Chen, "Artificial intelligence for fault diagnosis of rotating machinery: a review," Mechanical Systems and Signal Processing, vol. 108, pp. 33-47, 2018.

[24] J. H. Thrall, X. Li, Q. Li et al., "Artificial intelligence and machine learning in radiology: opportunities, challenges, pitfalls, and criteria for success," Journal of the American College of Radiology, vol. 15, no. 3, pp. 504-508, 2018. 